\title{
Novos registros em Tillandsia L. (Bromeliaceae, Tillandsioideae) para o Rio Grande do Sul, Brasil
}

\author{
New records in Tillandsia L. (Bromeliaceae, Tillandsioideae) for Rio Grande do Sul, Brazil
}

\author{
Henrique Mallmann Büneker ${ }^{1,2,4}$, Rodrigo Corrêa Pontes ${ }^{1,3}$ \& Leopoldo Witeck-Neto ${ }^{1}$
}

\begin{abstract}
Resumo
São registradas pela primeira vez para a flora do estado do Rio Grande do Sul (Brasil) Tillandsia loliacea Mart. ex Schult.f. e Tillandsia pohliana Mez, sendo também redescoberta Tillandsia bandensis Baker neste estado e Brasil. São fornecidas descrições, fotografias e dados de suas distribuições geográficas.

Palavras-chave: Tillandsia bandensis, Tillandsia loliacea, Tillandsia pohliana, Brasil meridional.
\end{abstract}

\begin{abstract}
In this short note are recorded for the first time for Rio Grande do Sul (Brazil) Tillandsia loliacea Mart. ex Schult.f. and Tillandsia pohliana Mez, and Tillandsia bandensis Baker was rediscovered in the same state and Brazil. We provide descriptions, photographs and geographical distribution for the species.
\end{abstract}

Key words: Tillandsia bandensis, Tillandsia loliacea, Tillandsia pohliana, Southern Brazil.

O gênero Tillandsia L., dentre as Bromeliaceae, é o que apresenta o maior número de espécies, cerca de 700 (Gouda et al. 2014) dispersas pelas três Américas como epífitas, rupícolas, terrícolas ou saxícolas, habitando os mais diversos ambientes (Leme \& Marigo 1993). Para o Brasil são citadas 87 espécies de Tillandsia, sendo que destas 50 são endêmicas (Forzza et al. 2014). Para o estado do Rio Grande do Sul (sul do Brasil) são citadas 28 espécies de Tillandsia, correspondendo a cerca de $32 \%$ das espécies deste gênero citadas para o Brasil, configurando-se como o estado brasileiro com maior diversidade específica em Tillandsia, (Forzza et al. 2014; Büneker et al. 2014), destas 19 são consideradas ameaçadas de extinção neste estado (Rio Grande do Sul 2003).

Esta nota científica apresenta dois registros inéditos de Tillandsia para o Rio Grande do Sul, Tillandsia loliacea Mart. ex Schult.f. e Tillandsia pohliana Mez, citadas até então apenas para outros estados brasileiros e outros países. Além disto, é confirmada a ocorrência de Tillandsia bandensis Baker para o Brasil após 57 anos de sua exclusão da flora brasileira por Smith (1956), sendo a espécie no país restrita ao estado do Rio Grande do Sul. Descrições e fotografias, bem como dados sobre suas distribuições geográficas e habitat são fornecidos com objetivo de subsidiar o reconhecimento dos três táxons.

O estudo foi baseado em coletas a campo, revisão da literatura especializada (Baker 1887, 1889; Mez 1895, 1896, 1935; Smith 1956; Smith \& Downs 1977; Tardivo 2002; Winkler 1982) e revisão de todos espécimes de Tillandsia depositados nos herbários: HAS, HDCF, HURG, HVAT, ICN, MPUC, PACA, PEL, RB, SMDB, SP e SPF, sendo que todos exemplares das espécies, aqui tratadas, encontrados para o Rio Grande do Sul foram citados em "material examinado". Também foram consultadas coleções typi através dos acervos digitais dos herbários: $\mathrm{K}, \mathrm{M}, \mathrm{P}$ e W. O material testemunho coletado, citado em "material examinado", foi depositado nos herbários SMDB e HDCF (acrônimos segundo Thiers 2014). Estes

\footnotetext{
${ }^{1}$ Colégio Politécnico da Universidade Federal de Santa Maria, Curso Técnico em Paisagismo, Av. Roraima, 1000, 97105-900, Camobi, Santa Maria, RS, Brasil.

${ }^{2}$ Universidade Federal de Santa Maria, Herbário do Depto. Ciências Florestais, Av. Roraima, 1000, 97105-900, Camobi, Santa Maria, RS, Brasil.

${ }^{3}$ Universidade Federal de Santa Maria, Laboratório de Pesquisa do Depto. Geociências (NEA/SAGEO), Núcleo em Estudos Ambientais e Ciência do Solo Aplicados à Geomorfologia, , Av. Roraima, 1000, Camobi, 97105-900, Santa Maria, RS, Brasil.

${ }^{4}$ Autor para correspondência: henriquebuneker@mail.ufsm.br
} 
dados foram obtidos ao decorrer dos anos de 2012 a 2014. As descrições morfológicas das espécies foram elaboradas a partir de espécimes coletados, cultivados até florescimento e posteriormente herborizados e seguem terminologia utilizada por Smith \& Downs (1977) com adaptações sugeridas por Scharf \& Gouda (2008).

1. Tillandsia bandensis Baker, Journal of Botany, British and Foreign 25: 234. 1887. Tipo: URUGUAI. s.d., Tweedie s.n. (Holótipo K!).

Fig. 1b-d

Erva epífita, saxícola ou rupícola, caulescente, cespitosa, quando florida 10-20 cm compr. Folhas 4-7, dísticas; bainha ovada, ca. 0,7 × 0,4 cm compr.; lâminas subcilíndrico-canaliculadas, 2,5-9 $\times 0,2 \mathrm{~cm}$, suberetas ou patentes, retas, cinéreas, tomentoso-lepidotas com escamas conspícuas na base da face abaxial. Inflorescência simples, ereta. Pedúnculo delgado, 5-9 cm compr., verde ou vináceo, lepidoto. Brácteas pedunculares 1-3, esparsas, $1-5 \times$ ca. $0,6 \mathrm{~cm}$, as da base foliáceas, densamente lepidotas; a superior geralmente locada na porção mediana do pedúnculo, estreito-elíptica, ecarenada, verde ou vinácea, lepidota na base e no ápice, ápice agudo. Porção fértil da inflorescência laxa, 1-4 flora, 1-2 cm compr.; ráquis conspícua, vinácea a esverdeada, glabra. Brácteas florais oval-elípticas, ca. $0,9 \times 0,13 \mathrm{~cm}$, ecarenadas, vináceas, mais curtas que as sépalas, ápice agudo e lepidoto na face abaxial. Flores dísticas, odoríferas, curto-pediceladas, eretas, adpressas a ráquis; pedicelos verdes, ca. 0,15 cm compr. Sépalas estreito-elípticas, ca. $0,75 \times 0,12 \mathrm{~cm}$, ecarenadas, vináceas, glabras, conatas na base por $0,1-0,2$ $\mathrm{cm}$, ápice agudo. Pétalas 1,4-1,7 × ca. 0,7 cm; unha linear, branca; lâmina elíptica a obovada, azulada, revoluta. Estames inclusos; filetes lineares, brancos; anteras amarelas, excedendo o comprimento do pistilo. Pistilo incluso; ovário esverdeado, elíptico; estilete branco, cilíndrico. Fruto cápsula ca. $2 \mathrm{~cm}$ compr., cilíndrica.

Material examinado: BRASIL. RIO GRANDE DO SUL: Alegrete, Cerro do Tigre, fl., 14.IX.2012, H.M. Büneker 102, R.C. Pontes \& L. Witeck (HDCF, SMDB).

Citada para o Brasil (Rio Grande do Sul) por Mez (1896), entretanto excluída da flora brasileira há 59 anos (Smith 1956), T. bandensis foi reencontrada, voltando a ser citada dentre a flora riograndense. Segundo Smith \& Downs (1977) $T$. bandensis ocorre na Bolívia, Paraguai, Uruguai, Argentina e através deste artigo volta a ser citada para o Brasil. Neste é restrita à região oeste do estado do Rio Grande do Sul, no Bioma Pampa, sendo sua única população relatada para a localidade conhecida como Cerro do Tigre (Fig. 1a), onde é encontrada como saxícola ou rupícola (Fig. 1b), hábito diferente do relatado por Smith \& Downs (1977), que a cita apenas como epífita. Cabe salientar que o espécime MPUC 3317, constante no banco de dados online deste herbário, identificado como T. bandensis, coletado em 1984 por C.S.A. Martins s.n. em Viamão (Rio Grande do Sul), não foi localizado no acervo do respectivo herbário e, provavelmente, trata-se de um erro de identificação, visto que a região em questão encontra-se bem amostrada por diversos estudos (e.g. Boldrini et al. 1998; Ferreira 2010; Leite et al. 2004; Musskopf 2006; Oliveira et al. 2005; Setubal \& Boldrini 2010), e coletas posteriores de $T$. bandensis não foram localizadas.

A primeira citação de sua ocorrência para o Rio Grande do Sul deve-se a Mez que, na obra Flora Brasiliensis (1895), a partir de coleta de Tweedie, a descreve como Tillandsia recurvata var. majuscula citando "Habitat in Brasilia australi, loco ignoto". Um ano mais tarde, em Monographiae Phanerogamarum (1896), o mesmo autor considera $T$. recurvata var. majuscula como sinônimo de T. bandensis e cita sua ocorrência para "Brasiliae prov. Rio Grande do Sul: Tweedie, in herb. Mus. Brit.". Posteriormente em diversas obras T. bandensis permaneceu sendo citada para o Rio Grande do Sul (e.g. Mez 1896; Hassler 1919), porém todas em referência à coleta de Tweedie e citações de Mez. Em 1956 Smith a exclui da flora brasileira fornecendo a seguinte justificativa: "This species has been cited from Brazil on the basis of the type, which actually came from Uruguay". Porém este autor considera erroneamente a coleta do Uruguai de Tweedie, pertencente ao acervo do herbário K (Holótipo de T. bandensis) como a mesma citada por Mez para o Rio Grande do Sul. Diversas tentativas de resgatar a exsicata citada por Mez foram realizadas, porém sem sucesso. Cabe salientar ainda que o naturalista J. Tweedie esteve na região onde $T$. bandensis foi reencontrada (Ollerton et al. 2012; Stafleu \& Cowan 1986).

Tillandsia bandensis pode ser reconhecida pelas flores conspícuas, odoríferas, pétalas azuis e brácteas florais vináceas. Difere morfologicamente de Tillandsia mallemontii Glaziou ex Mez (espécie morfologicamente similar), que ocorre na região do domínio da Mata Atlântica também no Rio Grande do Sul (Forzza et al. 2014), por apresentar lâminas 

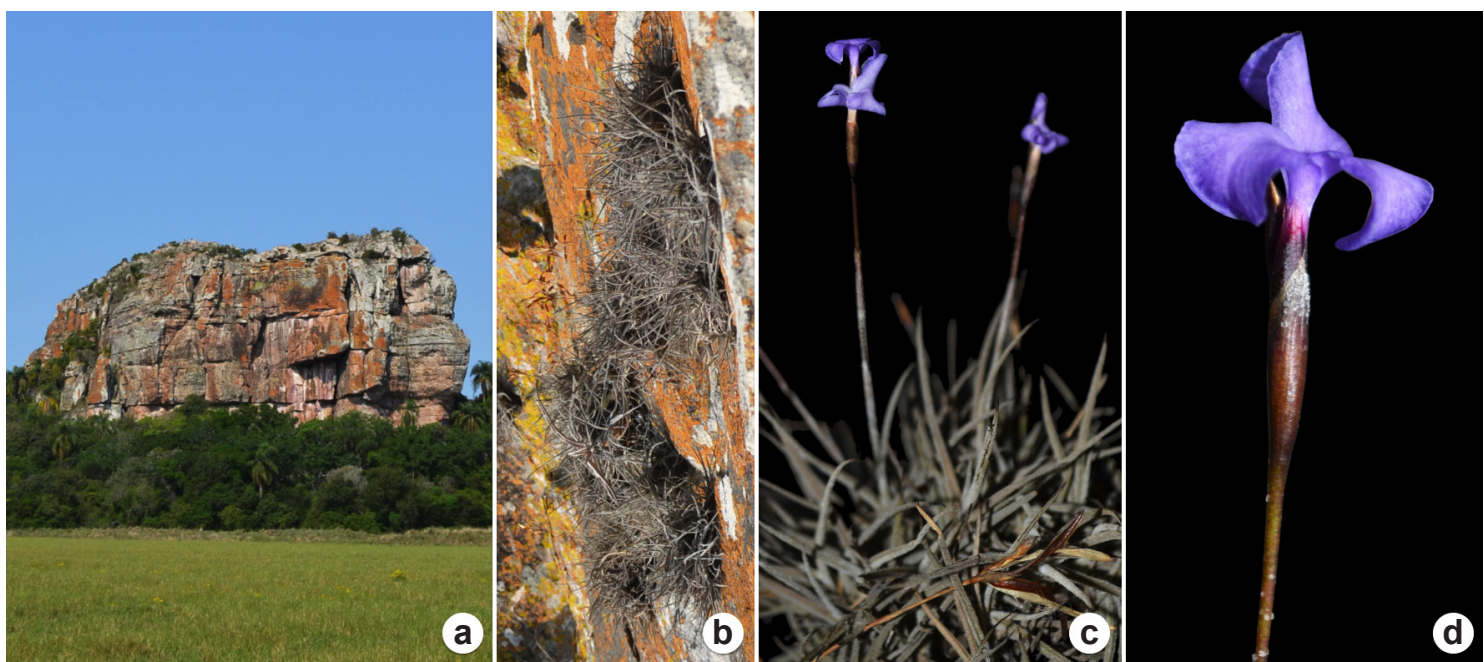

Figura 1 - a. Ambiente de Tillandsia bandensis no Cerro do Tigre, Alegrete, Rio Grande do Sul, Brasil. b-d. Tillandsia bandensis - b. hábito in situ; c. Hábitof értil; d. detalhe da inflorescência (b-d H.M. Büneker 102 et al.).

Figure 1- a. Environment of Tillandsia bandensis in Cerro do Tigre, Alegrete, Rio Grande do Sul, Brazil. b-d. Tillandsia bandensis - b. habit in situ; c. habit fertile; d. detail of inflorescence (b-d H.M. Büneker 102 et al.).

foliares retas e subereto-patentes ( $v s$. lâminas foliares arqueadas e reflexas), pedúnculo com uma bráctea na região mediana ( $v s$. pedúnculo desprovido de brácteas na região mediana) e brácteas florais e sépalas vináceas ( $v s$. brácteas florais e sépalas esverdeadas).

2. Tillandsia loliacea Mart. ex Schult.f., Systema Vegetabilium 7(2): 1204. 1830. Tipo: BRASIL. BAHIA: Habitat in rupibus M. Sancti, 1818, Martius s.n. (Holótipo M!). Fig. 2a-c

Erva epífita, de caule curto, cespitosa, quando florida 6-14 cm compr. Folhas 30-40, polísticas; bainha estreito elípticas a oblongas, $0,3-0,4 \times$ 0,4-0,6 cm, glabra; lâminas estreito-triangulares, côncavas, ca. 2,5 × 0,6 cm, eretas ou suberetas, raramente arqueado-secundas, denso cinéreolepidotas. Inflorescência simples, ereta a arqueada. Pedúnculo 3-8 cm compr., esverdeado, lepidoto. Brácteas pedunculares 4-5, lanceoladas, igualando os entrenós, $0,8-1,2 \times 0,2-0,3 \mathrm{~cm}$, esverdeadas a cinéreas, lepidotas, ápice agudo. Porção fértil da inflorescência laxa, 3-7 flora, 2-4,5 cm compr., algumas vezes sinuosa. Brácteas florais elípticas, $0,7-1 \times 0,4-0,5 \mathrm{~cm}$, ecarenadas, esverdeadas a verde-cinéreas, lepidotas, ápice agudo, as basais ultrapassando o comprimento das sépalas, as dos terços superior menores que as sépalas. Flores dísticas, subsésseis, eretas ou suberetas, adpressas a ráquis; ráquis visível do lado oposto a flor, lepidota. Sépalas lanceoladas, $0,5-0,8 \times$ $0,2-0,4 \mathrm{~cm}$, ecarenadas, esverdeadas, glabras ou esparsamente lepidotas no terço superior da face abaxial, breve e igualmente conatas na base, ápice agudo. Pétalas liguliformes, $0,6-1 \times 0,3-0,4 \mathrm{~cm}$, amarelo-vívidas; unha sublinear; lâmina com ápice arredondado. Estames inclusos, superando o pistilo; filetes lineares. Pistilo incluso; ovário curto-cilíndrico. Fruto cápsula ca. 4,5 cm compr., cilíndrica, apiculada.

Material examinado: BRASIL. RIO GRANDE DO SUL: São Francisco de Assis, fr., 16.XII.2013, H.M. Büneker $247 \&$ L. Witeck (HDCF); Unistalda, fr., 7.IX.2012, E. Valduga 414 (RB, HUCS).

Tillandsia loliacea ocorre segundo Smith \& Downs (1977) na Bolívia, Brasil, Paraguai e Argentina. Na lista de espécies da Flora do Brasil (Forzza et al. 2014) sua ocorrência é registrada para o Distrito Federal e os estados de Alagoas, Bahia, Ceará, Piauí, Rio Grande do Norte, Sergipe, Mato Grosso do Sul, Mato Grosso, Espírito Santo, Minas Gerais, São Paulo e Paraná. No Rio Grande do Sul foi encontrada como epífita em capões de mata, em vegetação arbóreo-aberta associadas a cornijas e cerros (Fig. 2d), na região oeste do estado (inclusa no Bioma Pampa), conhecida popularmente no meio científico como zona dos areais. Foram localizadas populações nos municípios de São Francisco de Assis e Unistalda, porém acredita-se que ocorra descontinuamente em capões de mata até a divisa com a Argentina, onde também ocorre. 

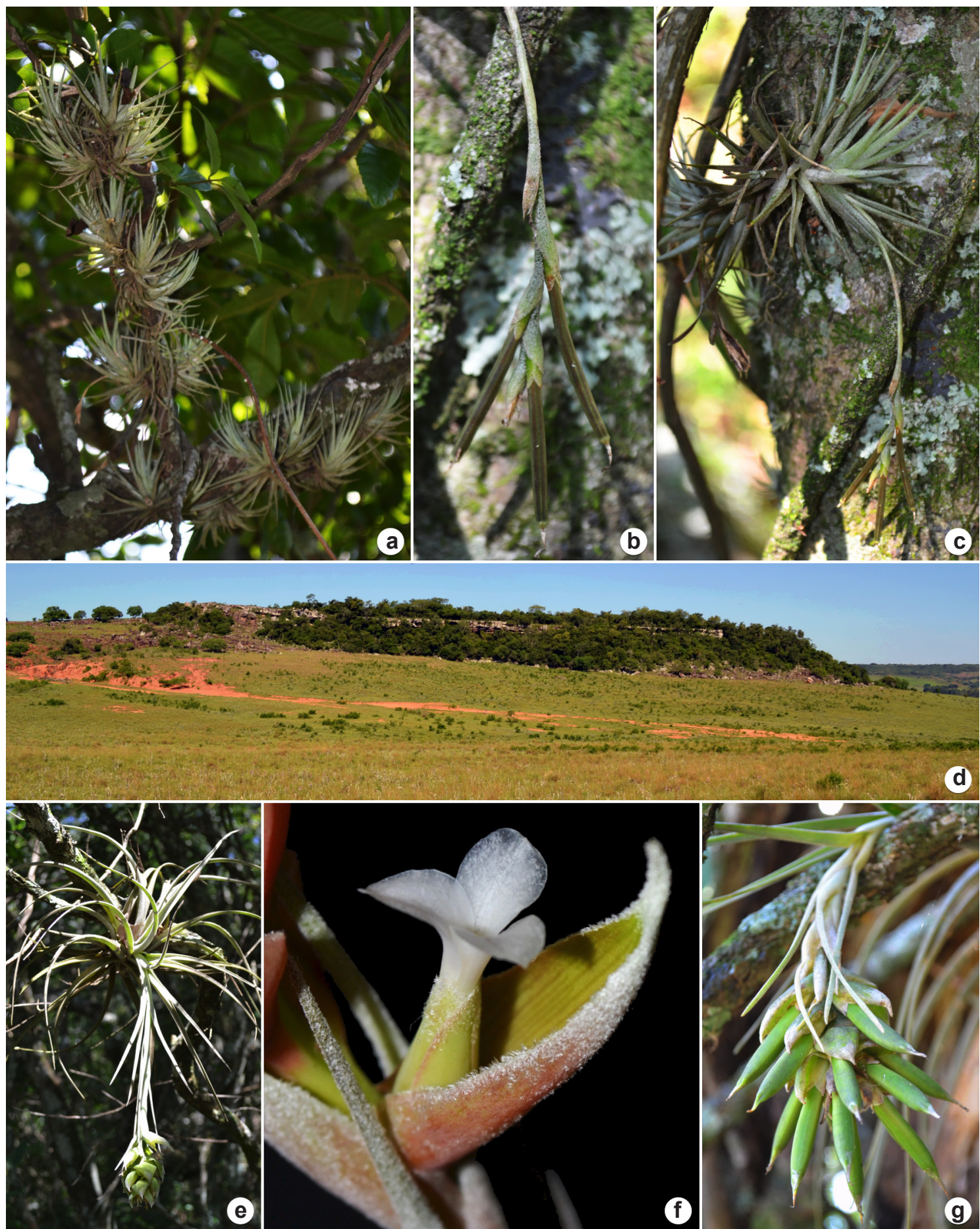

Figura 2 -a-c. Tillandsia loliacea - a. visão geral de um grupo de espécimes; b. detalhe da inflorescência frutificada; c. hábito (a-c H.M. Büneker 247 \& L. Witeck). d. cornija com capão de mato em São Francisco de Assis, Rio Grande do Sul, Brasil, ambiente de ocorrência de Tillandsia loliacea e Tillandsia pohliana. e-g. Tillandsia pohliana - e. hábito in situ; f. detalhe da inflorescência; g. detalhe da inflorescência frutificada (e-f H.M. Büneker 122 \& L. Witeck; g H.M. Büneker 165 et al.).

Figure 2 - a-c Tillandsia loliacea - a. overview of a group of specimens; b. detail of fruited inflorescence; c. habit (a-c H. M. Büneker 247\& L. Witeck). d. cornice with bushes in São Francisco de Assis, Rio Grande do Sul, Brazil, environment of occurrence of Tillandsia loliacea and Tillandsia pohliana. e-g. Tillandsia pohliana-e. habit in situ; f. detail of inflorescence; g. detail of fruited inflorescence (e-f H.M. Büneker 122 \& L. Witeck; g H.M. Büneker 165 et al.). 
Tillandsia loliacea pode ser facilmente reconhecida por ter folhas denso cinéreo-lepidotas (Fig. 2a-c) e flores dísticas, com pétalas de amarelo-vívido. A espécie pode ser confundida com Tillandsia tricholepis Baker, que também ocorre no Rio Grande do Sul. Desta T. loliacea difere por apresentar caule curto (vs. alongado), folhas cinéreas ( $v s$. esverdeadas), inflorescência laxa (vs. congesta) e pétalas amarelo-vívidas (vs. amarelo pálidas).

3. Tillandsia pohliana Mez, Flora Brasiliensis 3(3): 597. 1894. Tipo: BRASIL. MINAS GERAIS: São Miguel, s.d., Pohl 3658 (Holótipo W!); Barbacena, s.d., Glaziou 13242 (Sintipo P!).

Fig. 2e-g

Erva epífita, caule curto, quando florida 15-36 cm compr. Folhas 18-42, polísticas; bainha ca. $0,8 \times 1 \mathrm{~cm}$, pouco distinta; lâminas estreitotriangulares, côncavas, 12-20 × 1-1,6 cm, eretas ou suberetas, arqueadas, crassas, densamente lepidotas, cinéreas. Inflorescência simples, arqueada ou raramente subereta. Pedúnculo curvado, 13-20 cm compr., branco-esverdeado. Brácteas pedunculares imbricadas, 3-7 × ca. 1,5 $\mathrm{cm}$, as basais foliáceas, as dos terços superiores elípticas, lepidotas, cinéreas, ápice longamente acuminado. Porção fértil da inflorescência congesta, 6-15 flora, 3,5-8 cm compr., globosa a subcilíndrica. Brácteas florais oval-elípticas, $1,9-2,5 \times 1-1,7 \mathrm{~cm}$, patentes ou subpatentes, infladas, ecarenadas, róseo-alaranjadas a amareloesverdeadas, densamente lepidotas na face abaxial, ápice agudo a atenuado-acuminado. Flores polísticas, ca. $2 \mathrm{~cm}$ compr., curtopediceladas, suberetas. Sépalas ovado-elípticas, subcoriáceas, $1,1-1,5 \times 0,5-0,7 \mathrm{~cm}$, ecarenadas a levemente carenadas, amarelo-esverdeadas, margem avermelhada, breve e igualmente conatas na base por ca. $0,1 \mathrm{~cm}$., ápice agudo e lepidoto na face abaxial. Pétalas $18-2,2 \times 0,5-0,6 \mathrm{~cm}$, brancas; unha sublinear; lâmina elíptico-obovada, margem hialina, ápice cuneado-atenuado. Estames inclusos; filetes plicados na região superior; anteras lineares. Pistilo incluso; ovário obovóide. Fruto cápsula, ca. $4 \mathrm{~cm}$ compr., robusta, cilíndrica, apiculada.

Material examinado: BRASIL. RIO GRANDE DO SUL: Júlio de Castilhos, Fazenda Quebra Dentes, epífita na mata ciliar, 13.XI.2014, fl., H.M. Büneker 368 et al. (HDCF); São Francisco de Assis, 14.XII.2012, fr., H.M. Büneker $122 \& L$. Witeck (HDCF, SMDB); 2.V.2013, fr., H.M. Büneker 165, R.C. Pontes \& L. Witeck (HDCF); 16.XII.2013, fr., H.M. Büneker $243 \&$ L. Witeck (HDCF); Fazenda Joaquim Paz, 26.XI.2007, fl., E. Freitas 433 (HVAT).
Tillandsia pohliana ocorre, segundo Tardivo (2002), na região dos Andes, no Peru, Bolívia, Argentina e no Brasil. No Brasil ocorre no Distrito Federal e nos estados do Ceará, Paraíba, Pernambuco, Goiás, Mato Grosso do Sul, Mato Grosso, Minas Gerais, São Paulo e Paraná (Forzza et al. 2014). No Rio Grande do Sul foram localizadas duas populações: uma como epífita em capões de mata, em vegetação arbóreo-aberta associada a cornijas e cerros (Fig. 2d), na região oeste do estado (município de São Francisco de Assis), assim como T. loliacea; e outra, atipicamente como epífita em dossel de mata ciliar, às margens do curso médio do rio Toropi (município de Júlio de Castilhos), no rebordo do planalto meridional, na região central do estado, localidade onde sua população encontrase ameaçada pelos represamentos previstos com a implantação de Pequenas Centrais Hidrelétricas (Marchiori et al. 2014).

Tillandsia pohliana pode ser facilmente reconhecida por apresentar brácteas florais róseoalaranjadas a amarelo-esverdeadas amplamente oval-elípticas e infladas, pétalas brancas, e cápsulas robustas (Fig. 2e-g). A espécie pode ser confundida com Tillandsia recurvifolia Hook., que também ocorre no Rio Grande do Sul, podendo ser diferenciada desta pelo pedúnculo em geral maior, com até $20 \mathrm{~cm}$ compr. (vs. pedúnculo com até $13 \mathrm{~cm}$ compr.) e pelas brácteas florais róseo-alaranjadas a amarelo-esverdeadas, denso lepidotas na face abaxial (vs. róseas, glabras ou esparso lepidotas apenas no ápice da face abaxial).

\section{Agradecimentos}

Ao Colégio Politécnico da Universidade Federal de Santa Maria, seu diretor, Valmir Aita, a Marta Von Ende, e ao coordenador do Curso Técnico em Paisagismo, Marcelo Antônio Rodrigues, que proporcionaram as viagens até os ambientes naturais das espécies do gênero Tillandsia, viagens a eventos científicos, além de também cederem espaço para abrigar a coleção de Bromeliaceae. Às professoras Thais Scotti do Canto-Dorow e Liliana Essi, as contribuições na organização desta nota, e a Kelen Pureza Soares, Lucas Coelho de Assis e Elton Martinez Carvalho Leme, as produtivas discussões taxonômicas.

\section{Referências}

Baker, J.G. 1887. Synopsis of Tillandsieae. Journal of Botany 25: 211-214.

Baker, J.G. 1889. Handbook of the Bromeliaceae. George Bell \& Sons, London. 264p. 
Boldrini, I.I.; Miotto, S.T.S.; Longhi-Wagner; Pillar, V. de P. \& Marzall, K. 1998. Aspectos florísticos e ecológicos da vegetação campestre do Morro da Polícia, Porto Alegre, RS, Brasil. Acta Botanica Brasilica 12: 89-100.

Büneker, H.M.; Pontes, R.P. \& Soares, K.P. 2014. Duas novas espécies de Tillandsia L., subgênero Anoplophytum (Beer) Baker (Bromeliaceae, Tillandsioideae) para a flora sul brasileira. Iheringia Série Botânica 69: 89-96.

Ferreira, P.M. de A. 2010. Flora campestre rara, endêmica ameaçada dos morros graníticos de Porto Alegre, Rio Grande do Sul, Brasil. Dissertação de Mestrado. Universidade Federal do Rio Grande do Sul, Porto Alegre. 124p.

Forzza, R.C.; Costa, A.; Siqueira Filho, J.A.; Martinelli, G.; Monteiro, R.F.; Santos-Silva, F.; Saraiva, D.P.; Paixão-Souza, B.; Louzada, R.B. \& Versieux, L. 2014. Bromeliaceae in Lista de Espécies da Flora do Brasil. Jardim Botânico do Rio de Janeiro. Disponível em $<$ http://floradobrasil.jbrj.gov.br/jabot/ floradobrasil/FB6387>. Acesso em 14 junho 2014.

Gouda, E.J.; Butcher, D. \& Gouda, K. 2014 [continuously updated]. Encyclopedia of Bromeliads Version 3.1. Disponível em $<$ http://botu07.bio. uu.nl/bcg/encyclopedia/brome/>. Acesso em 30 setembro 2014.

Hassler, E. 1919. Bromeliacearum paraguariensiam conspectus. Annuaire du Conservatoire et du Jardin Botaniques de Genève 20: 268-341.

Leite, S.L. de C.; Luz, M. da; Lange, O. \& Guerra, T. 2004. Fisionomia e florística de um remanescente de mata ciliar do arroio Itapuã, Viamão, RS. Revista Brasileira de Biociências 2: 9-22.

Leme, E.C. \& Marigo, L.C. 1993. Bromélias na natureza. Marigo Comunicação Visual, Rio de Janeiro. 183p.

Marchiori, J.N.C.; Canto-Dorow, T.S. do; Büneker, H.M.; Essi, L.; Breier, T.B. \& Pontes, R.C. 2014. Campos e florestas no curso médio do Rio Toropi, Rio Grande do Sul (Brasil). Retrato de um admirável patrimônio ameaçado. Balduinia 45: 1-16.

Mez, C. 1895. Bromeliaceae. In Martius, C.F.P. von; Eichler, A.G. \& Urban, I. Flora Brasiliensis. München, Wien, Leipzig. Vol. 3, part. 2, pp. 172-634.

Mez, C. 1896. Bromeliaceae. In Candolle, A.P.P. de \& Candolle, A.C.P. de Monographiae phanerogamarum. Sumptibus Masson, Paris. Vol. 9, pp. 1-990.
Mez, C. 1935. Bromeliaceae. In Engler, A. (ed.) Das Pflanzenreich, Regni Vegetabilis Conspectus. W. Engelmann, Leipzig, Vol. 4, pp. 1-667.

Musskopf, M.L. 2002. Composição e distribuição ecológica de epífitos vasculares do Parque Estadual de Itapuã, Viamão, Rio Grande do Sul. Dissertação de Mestrado. Universidade Federal do Rio Grande do Sul, Porto Alegre. 58p.

Oliveira, M. de L.A.A. de; Balbueno, R.A. \& Senna, R.M. 2005. Levantamento florístico de fragmentos florestais na bacia hidrográfica do rio Gravataí, Rio Grande do Sul, Brasil. Iheringia Série Botânica 60: 269-284.

Ollerton, J.; Chancellor, G. \& Wyhe, J. van. 2012. John Tweedie and Charles Darwin in Buenos Aires. Notes and Records of the Royal Society of London 66: 115-124.

Rio Grande do Sul. 2003. Decreto $n^{\circ} 42.009$, de $1^{\circ}$ de janeiro de 2003. Lista final das espécies ameaçadas da flora do Estado do Rio Grande do Sul. Disponível em <http://www.al.rs.gov.br/legis/ M010/M0100099.ASP?Hid_Tipo=TEXTO\&Hid Tod a s Normas $=320 \&$ h Tex to $=\& \mathrm{Hid}_{-}$ IDNorma $=320>$. Acesso em 4 agosto 2014.

Scharf, U. \& Gouda, E.J. 2008. Bringing Bromeliaceae Back to Homeland Botany. Journal of the Bromeliad Society 58: 123-129.

Setubal, R.B. \& Boldrini, I.I. 2010. Floristic and characterization of grassland vegetation at a granitic hill in Southern Brazil. Revista Brasileira de Biociências 8: 85-111.

Smith, L.B \& Downs, R.J. 1977. Tillandsioideae (Bromeliaceae). Flora Neotropica Monograph 14: $663-1492$.

Smith, L.B. 1956. The Bromeliaceae of Brazil. Smithsonian Miscellaneous Collections 126: 1-450.

Stafleu, F.A. \& Cowan, R.S. 1986. Taxonomic literature. A selective guide to botanical publications and collections with dates, commentaries and types. Regnum Vegetabile 115: 1-926.

Tardivo, R.C. 2002. Revisão taxonômica de Tillandsia L. subgênero Anoplophytum (Beer) Baker (Bromeliaceae). Tese de Doutorado. Universidade de São Paulo, São Paulo. 238p.

Thiers, B. 2014 [continuously updated]. Index Herbariorum: a global directory of public herbaria and associated staff. New York Botanical Garden's Virtual Herbarium. Disponível em $<$ http:// sweetgum.nybg.org/ih/>. Acesso em 6 abril 2014.

Winkler, S. 1982. Die Bromeliaceae von Rio Grande do Sul. Documenta Naturae 3: 1-90. 